\title{
How to Decide about Robotic Surgery in Patients with Locally Advanced Gastric Cancer?
} \author{
Mircea Diculescu ${ }^{1,2}$, Catalin Vasilescu ${ }^{2,4}$, Teodora Manuc ${ }^{1}$ and Stefan Tudor ${ }^{4}$ \\ ${ }^{1}$ Department of Gastroenterology and Hepatology, Fundeni Clinical Institute, Bucharest, Romania \\ ${ }^{2}$ Carol Davila University of Medicine and Pharmacy, Bucharest, Romania \\ ${ }^{3}$ Department of Gastroenterology and Hepatology, Fundeni Clinical Institute, Bucharest, Romania \\ ${ }^{4}$ Department of General Surgery and Liver Transplantation, Fundeni Clinical Institute, Bucharest, Romania
}

Mircea Mănuc ${ }^{1,2}$, Catalin Dutei ${ }^{1,3}$, Matei R Bratu ${ }^{1,2}$, Bogdan Cristea ${ }^{2 *}$, Ioana Husar-Sburlan ${ }^{3}$, Bogdan Berbescu ${ }^{2}$,

Submission: August 20, 2019; Published: August 29, 2019

"Correspondence Author: Bogdan Cristea, University of Medicine and Pharmacy of Bucharest, Romania

Abstract

Aim: Surgery is the cornerstone in the treatment of gastric cancer and includes conventional open gastrectomy and minimally invasive techniques. Preoperative criteria should be established in order to decrease the rate of conversion to open surgery. To evaluate such criteria, we must focus on computer tomography and upper endoscopy workup.

Methods: This is a hospital-based observational retrospective study including 205 patients treated in Fundeni Clinical Institute, during the interval of 2008-2014. The patients were diagnosed with advanced gastric cancer according to endoscopic, computer-tomographic and histopathologic techniques. None of the patients received any neoadjuvant chemotherapy. 144 of patients underwent a curative surgical resection with D2 lymphadenectomy.

Results: Minimally invasive surgery was performed on 51 patients; other 26 patients were initially treated by MIS but during operation they were converted to open surgery. Open surgery was performed on 128 patients. Risk factors that led to converting an initially MIS intervention to open intervention comprise: Borrmann $1(\mathrm{p}=0.0275)$ identified by endoscopy, metastasis $(\mathrm{p}=0.0416)$, peritoneal carcinomatosis $(\mathrm{p}=0.0156)$ identified by CT scan. On the contrary, endoscopic staging Borrmann 3 proved to be a preventing factor against surgical conversion $(\mathrm{p}=0.0169)$.

Conclusion: A multivariate analysis of all prospective clinical, endoscopic and tomographic parameters is required to identify the patients with gastric cancer that could benefit more from the robotic platform. Endoscopic parameters such as the distance from cardia, distance to pylorus, the invasion of more than one gastric wall, the invasion of both vertical and horizontal portion, might constitute criteria for the selection of surgical methods.

Keywords: Robotic surgery; Locally advanced gastric cancer; Laparoscopic surgery; Gastric cancer surgery; Minimally invasive gastrectomy

\section{Introduction}

Gastric cancer is the fourth most common cancer and the second leading cause of cancer-related death worldwide [1]. Advanced gastric cancer comprises any tumor surpassing the submucosae, irrespective of the lymph node involvement [2]. Initial preoperative staging is essential and should include endoscopy with biopsies and a contrast-enhanced computed tomography scan of the thorax and abdomen \pm pelvis, for detecting regional invasion and metastatic disease [3]. Endoscopic ultrasound (EUS) is helpful in determining the proximal and distal extent of the tumor and provides further assessment of the $\mathrm{T}$ and $\mathrm{N}$ stages, although it is less useful in antral tumors [3]. In Europe alone more than $90 \%$ of the patients diagnosed with gastric tumors are already in an advanced stage at first presentation [4], this situation being due to the lack of screening programs across the continent $[5,6]$.

Surgery is the cornerstone in the treatment of gastric cancer and includes conventional open surgery gastrectomy (OS) and minimally invasive techniques (MIS) [7]. While all surgical specialties benefit from a minimally invasive approach, in gastric cancer, laparoscopic surgery is currently being regarded as the treatment of choice only for early gastric cancer. The indications and outcomes of laparoscopic gastrectomy for advanced gastric cancer remain controversial due to the technical difficulties and the lack of long-term results [8], however there are countries (South Korea, Japan, Taiwan) that promote it. Experienced surgeons have begun to treat patients with advanced gastric 
cancer using MIS and have reported acceptable short-term outcomes [9-11].

On several occasions a conversion from MIS to OS is necessary, after realizing the impossibility of oncologic resection by robotic surgery (RS) in a patient, thus creating important disadvantages. The conversion from RS to OS combines the high cost of the robotic surgery with the prolonged duration of operating theatre use; also, a greater morbidity in patients converted from RS to OS versus those who underwent OS from the beginning has been demonstrated in patients with colorectal cancer. To avoid these disadvantages, preoperative criteria should be established in order to decrease the rate of conversion from MIS to OS. To evaluate such criteria, we must focus on computer tomography (CT) and upper endoscopy workup, each of these implying disadvantages and limits.

\section{Materials and Methods}

\section{Study Population}

This is a hospital-based observational retrospective study including 205 patients treated in Fundeni Clinical Institute, during the interval of 2008-2014. The patients were diagnosed with advanced gastric cancer (AGC) according to endoscopic, computer-tomographic (CT) and histopathologic techniques [12].

\section{Ethics Committee Approval}

Ethics committee approval was received for this study from the ethics committee of Fundeni Clinical Institute. Approval Date:
21.12.2011. Decision No. 18848. All involved persons (subjects or legally authorized representative) gave their informed consent prior to study inclusion. All the cases diagnosed with AGC during that period were included in the study. The recruited cases were of both sexes, between 26 and 80 years old. None of the patients received any neoadjuvant chemotherapy. 144 of patients underwent a curative surgical resection with D2 lymphadenectomy.

\section{Clinical and Paraclinical Variables}

Retrieved data about patients included diagnosis year, age, gender, endoscopic variables (location of tumor, modified Borrman classification [12,13], extension to pylorus, cardia or duodenum, presence of active hemorrhage) and CT variables (presence of metastasis, peritoneal carcinomatosis, satellite lymph node enlargement, surpassing of gastric wall, duodenum invasion, intra-abdominal great vessels invasion, ascites and extension to pylorus and cardia).

\section{Assessment of Surgical Procedure}

Patients were classified in two groups according to the surgical procedure performed into: clasic open surgery (OS) and minimally-invasive surgery (MIS) - either laparoscopic or robotic (Figure 1). In all the patients referred to the robotic surgery an initial laparoscopic exploration was performed in order to evaluate carcinomatosis with very small masses and superficial liver metastasis that are under the limit of detection of CT investigation. In this patients palliative open surgery was further performed.

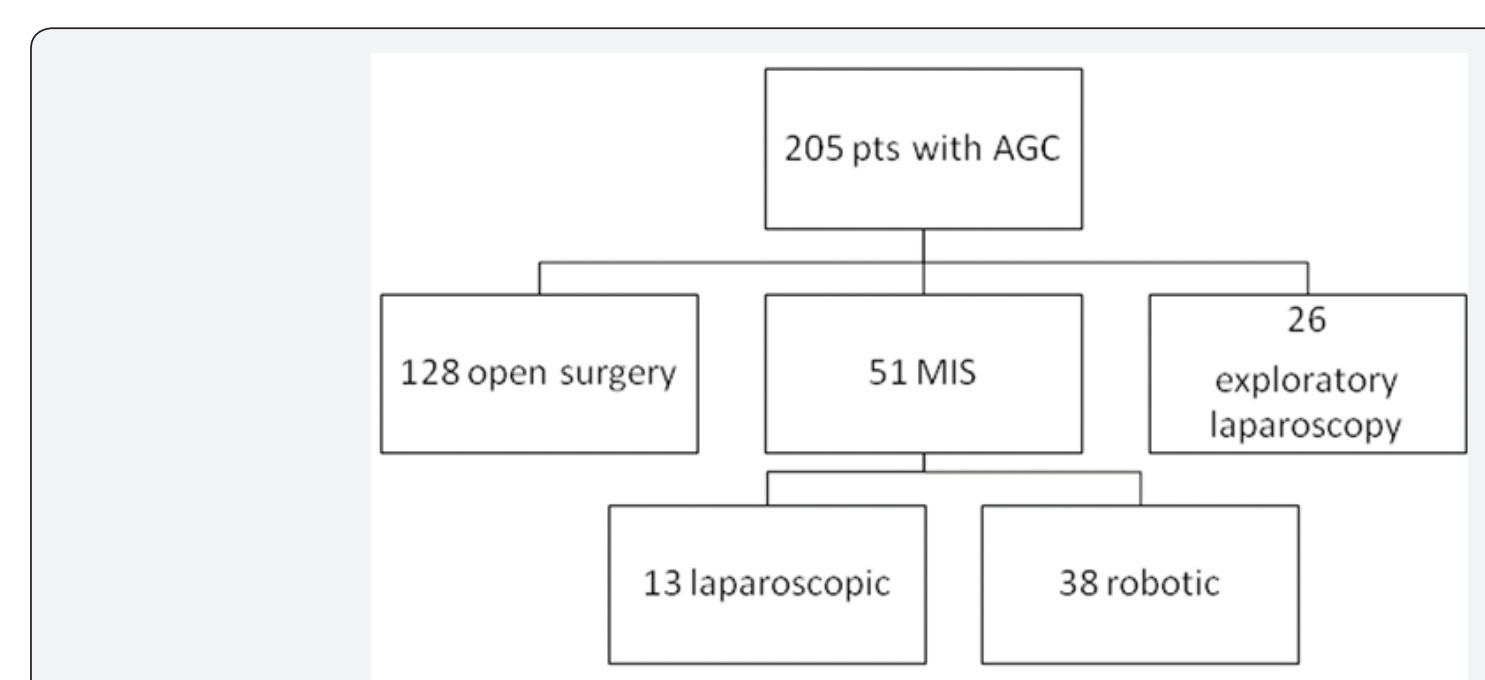

Figure 1: Patients classification.

\section{Statistical Analysis}

Data was introduced in Microsoft Excel 2007 (Microsoft Corporation, Redmond, WA, USA) worksheets and analysed statistically by Excel functions and GraphPad Prism6 (GraphPad Software, La Jolla, California, USA). Variable analysis was conducted by using Fisher's exact test on contingency tables.

\section{Results}

\section{General Data}

Of note, epidemiologic results show an increased number of patients with AGC in 2012 compared to the other years. There is a definite predominance ( $68 \%$ versus $32 \%$ ) of male patients. The peak interval of diagnosis is $65-75$ (32\%) years of age, 


\section{Cancer Therapy \& Oncology International Journal}

irrespective of gender. Distribution of incidence and gender is better shown in Figure 2. Results related to surgical procedures reveal that 144 patients underwent total resection according to the standard oncological recommendations, while the other 61 patients had palliative surgery. Minimally invasive surgery was performed on 51 patients. 26 patients were initially evaluated by laparoscopic exploration. Open surgery was performed from start on 128 patients.

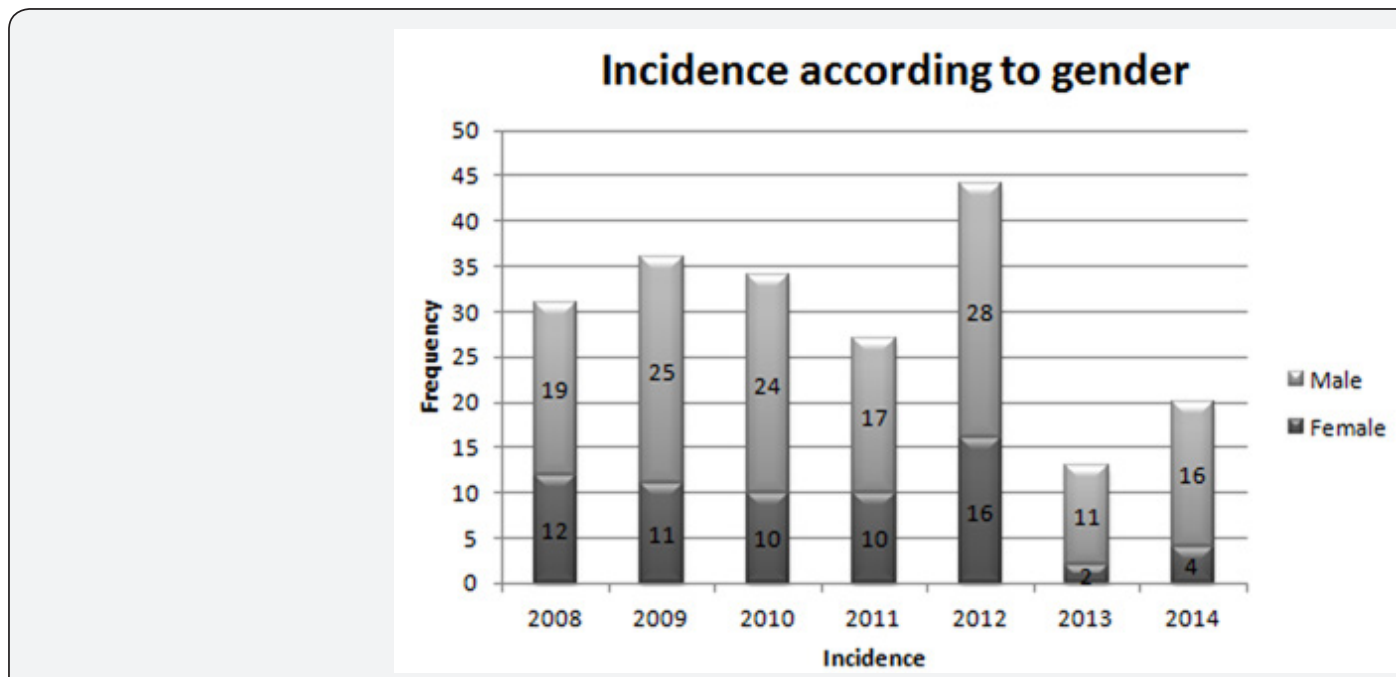

Figure 2: Incidence according to gender.

\section{Open Surgery versus minimally-Invasive Surgery}

Statistically significant was Borrmann type 2 for OS ( $\mathrm{p}=0.0038, \mathrm{RR}=1.26$ 95\% CI=1.09-1.46, OR=3.06 95\% CI=1.396.73); also Borrmann 3 was significant for MIS ( $p=0.0006$, $\mathrm{RR}=0.66, \quad 95 \% \quad \mathrm{CI}=0.49-0.88, \quad \mathrm{OR}=0.27, \quad 95 \% \quad \mathrm{CI}=0.13-0.55)$; extension to cardia/pylorus/duodenum was significant ( $\mathrm{p}=0.0048, \mathrm{RR}=1.23,95 \% \mathrm{CI}=1.06-1.42, \mathrm{OR}=2.66$ 95\% CI=1.205.88), as shown in Table 1.
Of the CT scan parameters, the presence of metastasis $(\mathrm{p}=0.0178, \mathrm{RR}=1.22,95 \% \mathrm{CI}=1.06-1.42, \mathrm{OR}=2.76,95 \% \mathrm{CI}=1.15-$ 6.58), the surpassing of gastric wall $(\mathrm{p}=0.0008, \mathrm{RR}=1.30,95 \%$ $\mathrm{CI}=1.13-1.51, \mathrm{OR}=3.59,95 \% \mathrm{CI}=1.63-7.89)$, the great vessel invasion $(\mathrm{p}=0.0184, \mathrm{RR}=1.28,95 \% \mathrm{CI}=1.11-1.47, \mathrm{OR}=4.97,95 \%$ $\mathrm{CI}=1.13-21.77)$ and the extension to cardia/pylorus ( $\mathrm{p}=0.0449$, $\mathrm{RR}=1.19,95 \% \mathrm{CI}=1.03-1.39, \mathrm{OR}=2.36,95 \% \mathrm{CI}=1.03-5.41$ ) also showed statistical relevance, as shown in Table 1.

Table 1: Paraclinical variables analyzed in predicting the surgery type - open versus minimally-invasive: Relative Risks, Odds Ratios, P-values.

\begin{tabular}{|c|c|c|c|}
\hline & Relative Risk (C.I. 95\%) & Odds Ratio (C.I. 95\%) & P-value \\
\hline Epidemiology & & & $0.90(0.46$ to 1.77$)$ \\
\hline Sex & $0.97(0.82$ to 1.15$)$ & $0.96(0.43$ to 2.14$)$ & 1.00 \\
\hline Age & $0.99(0.81$ to 1.20$)$ & & \\
\hline Upper Endoscopy & & & 0.31 \\
\hline Location & $1.09(0.92$ to 1.30$)$ & $1.43(0.75$ to 2.73$)$ & 0.52 \\
\hline VP & $0.94(0.80$ to 1.10$)$ & $0.79(0.42$ to 1.51$)$ & 0.33 \\
\hline Lesser curvature & $1.08(0.92$ to 1.27$)$ & $1.40(0.73$ to 2.69$)$ & 0.86 \\
\hline$>1$ VP & $0.98(0.83$ to 1.15$)$ & $1.52(0.79$ to 2.94$)$ & 0.25 \\
\hline OP & $1.10(0.94$ to 1.29$)$ & $1.63(0.73$ to 3.66$)$ & 0.26 \\
\hline$>1$ OP & $1.11(0.94$ to 1.31$)$ & & 0.48 to 1.78$)$ \\
\hline OP+VP & & $1.61(0.58$ to 4.49$)$ & 0.48 \\
\hline Borrmann type & $1.11(0.91$ to 1.34$)$ & $3.06(1.39$ to 6.73$)$ & 0.0038 \\
\hline Borrmann 1 & $1.26(1.09$ to 1.46$)$ & $0.27(0.13$ to 0.55$)$ & 0.0006 \\
\hline Borrmann ${ }^{*}$ & $0.66(0.49$ to 0.88$)$ & $0.70(0.33$ to 1.49$)$ & 0.42 \\
\hline Borrmann 3* & $0.91(0.73$ to 1.13$)$ & $1.45(0.46$ to 4.55$)$ & 0.60 \\
\hline Borrmann 4 & $1.08(0.86$ to 1.36$)$ & & \\
\hline Borrmann 5 & & & \\
\hline
\end{tabular}




\section{Cancer Therapy \& Oncology International Journal}

\begin{tabular}{|c|c|c|c|}
\hline Complications & & & 0.0148 \\
\hline $\begin{array}{c}\text { Extension cardia/pylorus/ } \\
\text { duodenum }\end{array}$ & $1.23(1.06$ to 1.42$)$ & $2.66(1.20$ to 5.88$)$ & 0.09 \\
\hline Active hemorrhage & $1.19(1.02$ to 1.40$)$ & $2.50(0.92$ to 6.82$)$ & 0.0178 \\
\hline CT & & & 0.25 \\
\hline Metastasis* & $1.22(1.06$ to 1.42$)$ & $2.76(1.15$ to 6.58$)$ & 1.00 \\
\hline Peritoneal carcinomathosys & $1.20(1.002$ to 1.44$)$ & $2.84(0.63$ to 12.81$)$ & 0.0008 \\
\hline Lymph node enlargement & $1.01(0.85$ to 1.19$)$ & $1.03(0.53$ to 2.002$)$ & 0.68 \\
\hline Surpassing of gastric wall* & $1.30(1.13$ to 1.51$)$ & $3.59(1.63$ to 7.89$)$ & 0.0184 \\
\hline Duodenum invasion & $1.14(0.83$ to 1.56$)$ & $2.02(0.23$ to 17.26$)$ & 1.00 \\
\hline Great vessel invasion* & $1.28(1.11$ to 1.47$)$ & $4.97(1.13$ to 21.77$)$ & 0.0449 \\
\hline Ascites & $1.06(0.77$ to 1.47$)$ & $1.34(0.27$ to 6.53$)$ & $2.36(1.03$ to 5.41$)$ \\
\hline Extension to cardia/pylorus* & $1.19(1.03$ to 1.39$)$ & . & \\
\hline
\end{tabular}

*the paraclinical variables with statistical significance VP: Vertical portion; OP: Horizontal portion; CT: Computer Tomography

\section{Resection versus Palliative Surgery}

Results regarding parameters correlated with palliative resection of tumor comprise the following endoscopic parameters with statistical significance: location on the vertical portion of the stomach $(p=0.04)$, location on more than one wall of the vertical portion $(\mathrm{p}=0.0002)$, location on both vertical and horizontal portion $(\mathrm{p}=0.03)$ and the presence of active hemorrhage $(\mathrm{p}=0.02)$. Of the computer-tomographic parameters, we retain the presence of metastasis $(\mathrm{p}<0.0001)$, peritoneal carcinomatosis $(\mathrm{p}<0.0001)$, surpassing of the gastric wall $(p=0.0001)$, invasion of duodenum $(p=0.0002)$, invasion of the great vessels $(p<0.0001)$, ascites $(p=0.0178)$ and extension to cardia/pylorus $(\mathrm{p}=0.01)$ with proven statistical significance. Borrmann 5 endoscopic staging proved to be a factor correlated with total resection $(\mathrm{p}=0.04)$ (Table 2).

Table 2: Paraclinical variables analysis indicative of total resection versus palliative surgery: Relative Risks, Odds Ratios, P-values.

\begin{tabular}{|c|c|c|c|}
\hline & Relative Risk (C.I. 95\%) & Odds Ratio (C.I. 95\%) & $P$ value \\
\hline \multicolumn{4}{|l|}{ Epidemiology } \\
\hline Sex & $1.01(0.83$ to 1.22$)$ & $1.03(0.54$ to 1.97$)$ & 1.00 \\
\hline Age & $1.02(0.85$ to 1.22$)$ & $1.08(0.59$ to 1.97$)$ & 0.87 \\
\hline \multicolumn{4}{|l|}{ Upper endoscopy } \\
\hline \multicolumn{4}{|l|}{ Location } \\
\hline$V P^{*}$ & $0.82(0.69$ to 0.98$)$ & 0.51 (0.26 to 0.97) & 0.04 \\
\hline Lesser curvature & $1.06(0.88$ to 1.27$)$ & $1.22(0.67$ to 2.22$)$ & 0.54 \\
\hline$>1 V P^{*}$ & $0.69(0.56$ to 0.84$)$ & $0.30(0.16$ to 0.56$)$ & 0.0002 \\
\hline $\mathrm{OP}$ & $1.04(0.86$ to 1.25$)$ & $1.15(0.62$ to 2.13$)$ & 0.64 \\
\hline$>10 \mathrm{P}$ & $0.94(0.79$ to 1.14$)$ & $0.84(0.46$ to 1.53$)$ & 0.64 \\
\hline$O P+V P^{*}$ & 0.78 ( 0.60 to 1.007$)$ & $0.48(0.24$ to 0.93$)$ & 0.03 \\
\hline \multicolumn{4}{|l|}{ Borrmann type } \\
\hline Borrmann 1 & $1.07(0.85$ to 1.36$)$ & $1.31(0.52$ to 3.28$)$ & 0.65 \\
\hline Borrmann 2 & $0.93(0.76$ to 1.13$)$ & $0.80(0.42$ to 1.49$)$ & 0.52 \\
\hline Borrmann 3 & $1.03(0.83$ to 1.27$)$ & $1.12(0.53$ to 2.36$)$ & 0.85 \\
\hline Borrmann 4 & $0.83(0.64$ to 1.07$)$ & $0.57(0.28$ to 1.15$)$ & 0.13 \\
\hline Borrmann $5^{* *}$ & 1.33 (1.12 to 1.58$)$ & 4.48 (1.01 to 19.89$)$ & 0.04 \\
\hline \multicolumn{4}{|l|}{ Complications } \\
\hline $\begin{array}{l}\text { Extension to Cardia/pylorus/ } \\
\text { duodenum }\end{array}$ & $0.85(0.69$ to 1.05$)$ & $0.61(0.32$ to 1.15$)$ & 0.14 \\
\hline Active hemorrhage* & $0.74(0.55$ to 0.99$)$ & $0.43(0.21$ to 0.87$)$ & 0.02 \\
\hline \multicolumn{4}{|l|}{$\mathrm{CT}$} \\
\hline Metastasis* & $0.42(0.29$ to 0.61$)$ & $0.11(0.056$ to 0.22$)$ & $<0.0001$ \\
\hline
\end{tabular}




\section{Cancer Therapy \& Oncology International Journal}

\begin{tabular}{|c|c|c|c|}
\hline Lymph node enlargement & $0.86(0.72$ to 1.02$)$ & $0.58(0.30$ to 1.13$)$ & 0.11 \\
\hline Surpassing of gastric wall* & $0.67(0.53$ to 0.84$)$ & $0.29(0.15$ to 0.55$)$ & 0.0001 \\
\hline Duodenum invasion* & $0.52(0.23$ to 0.63$)$ & $0.29(0.15$ to 0.55$)$ & 0.0002 \\
\hline Great vessel invasion* & $0.47(0.28$ to 0.78$)$ & $0.17(0.07$ to 0.41$)$ & $<0.0001$ \\
\hline Ascites* & $0.50(0.22$ to 1.10$)$ & $0.22(0.06$ to 0.78$)$ & 0.0178 \\
\hline Extension to cardia/pylorus* & $0.74(0.58$ to 0.96$)$ & $0.42(0.22$ to 0.80$)$ & 0.01 \\
\hline
\end{tabular}

VP, Vertical portion; OP, Horizontal portion; CT, computer tomography

*the paraclinical variables with statistical significance for palliative resection

**the paraclinical variable correlated with total resection

Minimally Invasive Surgery versus Conversion to Open $(p=0.0275)$ identified by endoscopy, metastasis $(p=0.0416)$,

\section{Surgery}

Risk factors that led to converting an initially MIS intervention to open intervention comprise: Borrmann 1 peritoneal carcinomatosis $(\mathrm{p}=0.0156)$ identified by CT scan. On the contrary, endoscopic staging Borrman 3 proved to be a preventing factor against surgical conversion $(\mathrm{p}=0.0169)$, as shown in Table 3.

Table 3: Paraclinic parameters involved in MIS conversion to OS versus OS: Relative Risks, Odds Ratios, P-values.

\begin{tabular}{|c|c|c|c|}
\hline & Relative Risk (C.I. 95\%) & Odds Ratio (C.I. 95\%) & P value \\
\hline \multicolumn{4}{|l|}{ Epidemiology } \\
\hline Sex & 0.81 (0.39 to 1.67$)$ & 0.73 (0.25 to 2.09$)$ & 0.61 \\
\hline Age & $0.76(0.40$ to 1.44$)$ & $0.66(0.24$ to 1.80$)$ & 0.44 \\
\hline \multicolumn{4}{|l|}{ Upper Endoscopy } \\
\hline \multicolumn{4}{|l|}{ Location } \\
\hline $\mathrm{VP}$ & $1.20(0.62$ to 2.29$)$ & $1.31(0.50$ to 3.44$)$ & 0.63 \\
\hline Lesser curvature & $0.83(0.44$ to 1.55$)$ & $0.75(0.29$ to 1.95$)$ & 0.63 \\
\hline$>1 \mathrm{VP}$ & $1.14(0.61$ to 2.15$)$ & 1.23 (0.47 to 3.23$)$ & 0.80 \\
\hline $\mathrm{OP}$ & $0.87(0.46$ to 1.63$)$ & $0.80(0.30$ to 2.12$)$ & 0.80 \\
\hline$>1 \mathrm{OP}$ & 1.09 (0.57 to 2.07$)$ & $1.14(0.43$ to 3.04$)$ & 0.80 \\
\hline $\mathrm{OP}+\mathrm{VP}$ & 1.07 (0.48 to 2.34$)$ & 1.11 (0.33 to 3.73$)$ & 1.00 \\
\hline \multicolumn{4}{|l|}{ Borrmann type } \\
\hline Borrmann 1* & $2.18(1.22$ to 3.91$)$ & 4.08 (1.17 to 14.18$)$ & 0.02 \\
\hline Borrmann 2 & $0.89(0.37$ to 2.16$)$ & 0.84 (0.23 to 3.07$)$ & 1.00 \\
\hline Borrmann $3^{* *}$ & 0.30 (0.10 to 0.92$)$ & $0.20(0.053$ to 0.76$)$ & 0.01 \\
\hline Borrmann 4 & 1.05 (0.52 to 2.11$)$ & $1.07(0.36$ to 3.14$)$ & 1.00 \\
\hline Borrmann 5 & $1.56(0.72$ to 3.40$)$ & $2.13(0.48$ to 9.34$)$ & 0.43 \\
\hline \multicolumn{4}{|l|}{ Complications } \\
\hline $\begin{array}{c}\text { Extension to cardia/pylorus/ } \\
\text { duodenum }\end{array}$ & $1.56(0.83$ to 2.96$)$ & 2.07 (0.68 to 6.23 ) & 0.24 \\
\hline Active hemorrhage & $1.59(0.78$ to 3.25$)$ & 2.19 (0.57 to 8.39$)$ & 0.29 \\
\hline \multicolumn{4}{|l|}{ CT } \\
\hline Metastasis* & 2.01 (1.11 to 3.64$)$ & $3.32(1.06$ to 10.36$)$ & 0.04 \\
\hline Peritoneal carcinomatosis* & $2.58(1.50$ to 4.46$)$ & 7.35 (1.36 to 39.56) & 0.01 \\
\hline Lymph node enlargement & $2.34(0.90$ to 6.04$)$ & $3.26(0.97$ to 10.92$)$ & 0.06 \\
\hline Surpassing of gastric wall & $1.73(0.94$ to 3.20$)$ & 2.47 (0.83 to 7.29$)$ & 0.15 \\
\hline Duodenum invasion & $2.38(1.23$ to 4.60$)$ & $6.52(0.64$ to 66.16$)$ & 0.10 \\
\hline Great vessel invasion & 2.15 (1.10 to 4.17$)$ & 4.45 (0.75 to 26.17$)$ & 0.17 \\
\hline Ascites & $1.52(0.54$ to 4.27$)$ & $2.04(0.27$ to 15.40$)$ & 0.59 \\
\hline Extension to cardia/pylorus & $1.52(0.78$ to 2.94$)$ & $1.98(0.62$ to 6.25$)$ & 0.36 \\
\hline
\end{tabular}

VP: Vertical portion; OP: Horizontal portion; CT: Computer Tomography 


\section{Cancer Therapy \& Oncology International Journal}

*risk factors for conversion of MIS to OS.

${ }^{* *}$ preventing factor against conversion of MIS to OS.

\section{Discussion}

The aim of this study is to find preoperative criteria for selection of patients in whom to begin with MIS, respectively robotic surgery. Based on CT and upper endoscopy parameters, we intend to identify: pylorus and duodenum invasion (due to difficulty of dissection at distal gastric pole); cardial and esophageal invasion (due to difficulty of dissection at proximal gastric pole and local anastomosis); lymph node enlargement/ masses (due to difficulty to perform D2); horizontal extension (due to complex types of resections - pancreas, spleen, left hepatic lobe, etc.) and invasion of great vessels. Also, metastasis and carcinomatosis contraindicates lymphadenectomy [14]. The only two situations in which they cannot be identified are represented by peritoneal carcinomatosis with very small masses and hepatic metastasis size less than $4 \mathrm{~mm}$. Such criteria would significantly help in treating more patients with AGC by MIS, without risking a switch to open surgery, major postoperative complications and mortality, or cancer recurrence.

It should be noted that in many centers that operate gastric cancer, the surgery usually begins with the laparoscopic exploration of the peritoneal cavity. After deciding the surgical indication, the standard steps are general anesthesia followed by insufflation and the placement of the video camera. In this way peritoneal metastasis (carcinomatosis) and small hepatic metastasis - under the detection limit of the CT scan - can be identified from the beginning. This approach clearly leads to a decrease in the number of unnecessary laparotomies. However, this protocol has two disadvantages as it increases both the operative time and the costs involved - the materials used (protective covers, surgical instruments dedicated to robotic surgery, etc.) if robotic surgery is intended.

Other authors propose the robotic approach from the beginning followed by open surgery in case of necessity due to technical difficulties. However, it is demonstrated that the conversion from MIS to OS is not harmless and implies a greater rate of complications, increasing the postoperative morbidity. For example, in colorectal laparoscopic surgery, conversion to open surgery of a laparoscopic intervention is an independent risk factor for the occurrence of fistulas, parietal suppurations and postoperative peritonitis. Of note, the results we achieved in this study should be enhanced by further investigations, until clear, universally valid criteria are established for the selection of gastric cancer patients to undergo robotic surgery. The realistic point of view is that variability (of cases, of the surgical team experience, of the volume of operations performed in the concerned institute) will always exist. Also, post-operative results of MIS and OS need to be compared, considering the operating time, number of retrieved lymph nodes, bleeding time both intra-operative and post-operative, survival rate [15-19].

\section{OS vs. MIS}

Following our analysis locally advanced gastric cancers type 2 Borrmann occur more frequently in the group of patients in which OS was performed compared to type 3 Borrmann patient in which MIS was preferred. The small number of cases analyzed, and the retrospective nature of this study make this observation difficult to interpret. It should be examined whether the type 2 Borrmann lesions represent an independent factor or if in association with invasion of cardia/pylorus.

The most important endoscopic finding of differentiation between the two groups is the endoscopic signs of extension to the cardia, on one hand, and to the pylorus and duodenum, on the other hand. It is easy to understand why the invasion of either of the two gastric poles of the stomach indicates open surgery. The invasion of the pylorus makes it technically difficult to close the duodenal stump. The invasion of the cardia often requires the intraoperative exploration of the superior gastric pole to establish the extension to the esophagus, possibly the submucosal extension of the malignant process. Tumor extension to the esophagus requires an esophageal resection that could require a thoracic approach. These situations can be solved by minimally invasive techniques but require a thorough preoperative planning. The information provided by the preoperative CT scan that may suggest a greater benefit of open surgery are the invasion of the cardia, the invasion of the pylorus, the surpassing the gastric wall with invasion of neighboring organs which indicates the need for a complex resection (gastric resection with splenectomy, liver resection, etc.). In these cases laparotomy is preferred. Evidence of large vessel invasion on CT scan guides surgeons to choose conservative treatment or palliative surgery.

\section{Complete Resection vs. Palliative Resection}

This choice cannot be completely separated from the previous discussion. However, it should be emphasized that some endoscopic findings bring arguments for a palliative approach: the localization of the gastric tumor (in the vertical portion of the stomach, across several walls, in both vertical and horizontal portions of the stomach) and the presence of active bleeding. Most authors tend to perform open surgery if palliative surgery is intended. In our experience, we have performed MIS in selected cases of palliative surgery with satisfying outcomes, patients benefiting from avoiding the stress and the longer healing process involved in a large laparotomy.

Certainly, the CT scan offers clear arguments whenever palliative surgery is in discussion. The CT scans performed for our patients offer useful data about the systemic dissemination of the disease (visceral metastasis and peritoneal carcinomatosis) and thus prevent an extended lymphadenectomy. Moreover, detecting ascites usually indicates the presence of peritoneal carcinomatosis, confirmed later by cytological examination of ascites fluid. 


\section{Cancer Therapy \& Oncology International Journal}

\section{Conversion from MIS to OS}

It should be reminded that a conversion from the OS to MIS is not without consequences, which has been demonstrated in laparoscopic colorectal surgery, underlining the importance of finding criteria for conversion risk evaluation. Our data provide thata polypoid endoscopic type (type 1 Borrmann) correlates with an increased risk of conversion, while type 3 Borrmann lesions occur more frequently in MIS group and rarely in the converted group. In 26 patients addressed to robotic surgery laparoscopic control of the peritoneal cavity reveals carcinomatosis with very small masses and superficial liver metastasis that are under the limit of detection of CT investigation. In these patient's palliative open surgery was applied.

Technological advances in the world of surgery have developed exponentially during these decades with undeniable advantages for patients. Industrial pressure, media and marketing elements have also contributed to the spread of these hi-tech, often very expensive methods. One such tendency promotes the introduction of the robotic surgery in many specialties. The first stage of feasibility assessment of robotic surgery is about to end. The DaVinci equipment can be used to operate almost everything. The key point is to establish which patients would benefit more from the use of such technology, considering that the indications of robotic surgery are currently extending from ECG to AGC.

\section{Conclusion}

The current study deals with finding criteria for selection of patients with gastric cancer that could benefit more from minimally invasive surgery specialty for the robotic platform. In order to asses each patient properly, a multivariate analysis of all prospective clinical, endoscopic and tomographic parameters is required. Endoscopic parameters such as the distance from cardia, distance to pylorus, the invasion of more than one gastric wall, the invasion of both vertical and horizontal portion, might constitute criteria for the selection of surgical methods. Until clear data is obtained, minimally invasive surgery in advanced gastric cancer has to be performed strictly in excellence centers of gastric surgery.

\section{References}

1. Crew KD, Neugut AI (2006) Epidemiology of gastric cancer. World J Gastroenterol 12(3): 354-362.

2. Saragoni L, Morgagni P, Gardini A, Marfisi C, Vittimberga G, et al (2013) Early gastric cancer: diagnosis, staging, and clinical impact. Evaluation of 530 patients. New elements for an updated definition and classification. Gastric Cancer 16(4): 549-554.
3. Waddell T, Verheij M, Allum W, Cunningham D, Cervantes A, et al. (2014) Gastric cancer: ESMO-ESSO-ESTRO Clinical Practice Guidelines for diagnosis, treatment and follow-up. Radiother Oncol 110: 189-194.

4. Koessler T, Roth A, Cacheux W (2014) Early gastric cancer: epidemiology, diagnostic and management. Rev Med Suisse 10(431): 1118-1122.

5. Shen L, Shan YS, Hu HM, Price T], Sirohi B, et al. (2013) Management of gastric cancer in Asia: resource-stratified guidelines. Lancet Oncol 14(12): e535-e547.

6. Leung WK, Wu MS, Kakugawa Y, Kim JJ, Yeoh KG, et al. (2008) Screening for gastric cancer in Asia: current evidence and practice. Lancet Oncol 9(3): 279-287.

7. Li QG, Li P, Tang D, Chen J, Wang DR (2013) Impact of postoperative complications on long-term survival after radical resection for gastric cancer. World J Gastroenterol 19(25): 4060-4065.

8. Shinohara T, Satoh S, Kanaya S, Ishida Y, Taniguchi K, et al. (2013) Laparoscopic versus open D2 gastrectomy for advanced gastric cancer: a retrospective cohort study. Surg Endosc 27(1): 286-294.

9. Hiki N (2013) Present features and future vision of laparoscopyassisted total gastrectomy (LATG). Gastric Cancer 16(4): 460-461.

10. Son T, Hyung WJ (2015) Robotic gastrectomy for gastric cancer. J Surg Oncol 112(3): 271-278.

11. Son T, Kwon IG, Hyung WJ (2014) Minimally invasive surgery for gastric cancer treatment: current status and future perspectives. Gut Liver 8(3): 229-236.

12. Japanese Gastric Cancer Association (2011) Japanese classification of gastric carcinoma: $3^{\text {rd }}$ English edition. Gastric Cancer 14(2): 101-112.

13. Larraga JO, Cossio SS, Guerrero AH, Pluma VH, Casillas JT (2003) The Borrmann classification. Interobserver and intraobserver agreement of endoscopists in an oncological hospital. Clin Transl Oncol 5(6): 345350 .

14. Dutei C, Sburlan, Vasilescu C, Manuc M, Diculescu M (2014) Predictive factors for choosing minimally invasive surgery in patients with advanced gastric cancer. United European Gastroenterology Journal Supplement 1

15. Procopic L, Tudor S, Manuc M, Diculescu M, Vasilescu C (2015) Open vs robotic radical gastrectomy for locally advanced gastric cancer. Int J Med Rob and Comp Ass Surg 12(3): 502-508.

16. Baek SJ, Lee DW, Park SS, Kim SH (2011) Current status of robotassisted gastric surgery. World J Gastrointest Oncol 3(10): 137-143.

17.Zong L, Seto Y, Aikou S, Takahashi T (2014) Efficacy evaluation of subtotal and total gastrectomies in robotic surgery for gastric cancer compared with that in open and laparoscopic resections: a metaanalysis. PLoS One 9: e103312.

18. Chen K, Xu XW, Mou YP, Pan Y, Zhou YC, et al. (2013) Systematic review and meta-analysis of laparoscopic and open gastrectomy for advanced gastric cancer. World J Surg Oncol 11: 182.

19. Chen K, Pan Y, Cai JQ, Xu XW, Wu D, et al. (2014) Totally laparoscopic gastrectomy for gastric cancer: a systematic review and meta-analysis of outcomes compared with open surgery. World J Gastroenterol 20: 15867-15878. 
his work is licensed under Creative Commons Attribution 4.0 License DOI: 10.19080/CTOIJ.2019.15.555901

\section{Your next submission with Juniper Publishers} will reach you the below assets

- Quality Editorial service

- Swift Peer Review

- Reprints availability

- E-prints Service

- Manuscript Podcast for convenient understanding

- Global attainment for your research

- Manuscript accessibility in different formats

( Pdf, E-pub, Full Text, Audio)

- Unceasing customer service

Track the below URL for one-step submission https://juniperpublishers.com/online-submission.php 